\title{
Spatial trends in surface runoff and influence of climatic and physiographic factors: A case study of watershed areas of Rawalpindi district
}

\author{
Atif Ali Khan , Muhammad Irfan Ashraf ${ }^{1}$, Sabeeqa Usman Malik', Saeed Gulzar ${ }^{1}$ and \\ Muhammad Amin' \\ ${ }^{1}$ Department of Forestry \& Range Management, PMAS Arid Agriculture University, Rawalpindi, Pakistan. \\ ${ }^{2}$ Institute of Geo-information and Earth Observation, PMAS Arid Agriculture University, Rawalpindi, Pakistan.
}

[Received: March 08, 2019 Accepted: June 05, 2019]

\begin{abstract}
Effect of climatic and physiographic factors on surface runoff is critical to study for soil conservation and water harvesting. In this study, the spatial variations of climatic and physiographic factors and their spatial correlation with surface runoff was investigated. The rainfall and temperature records were used for mapping climatic factors. Digital Elevation Model (DEM) was utilized in estimation and mapping of physiographic factors as well as watershed delineation and runoff estimation. The models were generated using runoff and influencing factors (rainfall, temperature, slope and elevation). The relationship between runoff and influencing factors was derived by developing statistically sound regression models. The spatial correlation indicated that the maximum surface runoff was generated in the areas receiving high rainfall $(>1450 \mathrm{~mm})$ whereas, runoff tend to decrease with rise in temperature above a certain value $\left(18{ }^{\circ} \mathrm{C}\right)$. The runoff also showed significant variability with slope and elevation changes. Maximum change in runoff was predicted by one unit change in temperature followed by elevation, slope and then rainfall. The regression model was found to be adequately fit to the predicted runoff by using influencing factors. The study identified potential water harvesting sites for sustainable water supply in Rawalpindi district.
\end{abstract}

Keywords: Runoff, hydrology, water sustainability, rainwater harvesting, soil conservation

\section{Introduction}

Sustainable development of water resources is necessary to achieve multi-dimensional social and economic growth of a country (Meshram et al., 2015). Watershed is an area of land that drains all the streams and rainfall water to a common point (USGS, 2017). Watersheds show variations in their hydrological response to the particular climatic and physiographic conditions of a region. These variations arise due to the surface and subsurface hydrological processes. The interaction of spatial, physiographic and climatic factors determines the hydrological response of a watershed (Kirkby et al., 2002).

Hydrology deals with the nature, movement and environmental functions of natural water (Younger et al., 2002). The runoff generated due to heavy rain influences the hydrological cycle. The surface runoff within a watershed is an important indicator for the assessment of water yield potential. Watershed potential is greatly helpful in designing soil and water conservation strategies (Shi et al., 2009). The variations in runoff can largely be explained by climatic factors. Long-term variations in runoff are highly consistent with climatic factors. The annual runoff magnitude is directly influenced by precipitation (Du and Shi, 2012). The rainfall intensity, its duration, distribution and magnitude have greater impact on runoff and sediment yield (dos Santos et al., 2017). Air temperature has minimal effect on runoff compared to rainfall. However, temperature may become more influential if it continues to increase over time (McCabe and Wolock, 2011).

Geographical information system (GIS) is helpful in mapping hydrological factors, watershed delineation and estimation of surface runoff (Mekonnen et al., 2016). Digital Elevation Models (DEMs) provide a sampled arrangement of elevation for ground positions at regular intervals. DEMs offer suitable terrain illustration such as land surface, hydrological limits and landscape traits (incline and angle). DEMs are frequently utilized for automated derivations of watersheds by identifying drainage features along with ridges, channel networks, drainage patterns and quantifying sub catchment together with size, length and slope (Garbrecht and Martz, 1999; Deng and Bauer, 2007). GIS based approach is usually applied to identify water flow direction and flow accumulation for every grid point in DEM (Jenson and Domingue, 1988). This tool can also be used for identification of potential rainwater harvesting sites (Munyao et al., 2010).

\footnotetext{
*Email: irfanashraf@uaar.edu.pk
} 
Physiographic characteristics such as elevation and slope are decisive in watershed related studies. Elevation surface in rainfall-runoff simulations is commonly represented by raster-based DEM (Wu et al., 2007). There is a strong correlation of surface runoff and elevation of the watershed (Garcia-Martino et al., 1996). Slope length along gradient regulates water flow and has important contribution in runoff generation (Garg et al., 2013). Water flow in the streams is greatly influenced by the physical properties of the catchment area. Size of watershed is an important element as well that contributes to stream flow (Rajib and Venkatesh, 2015). However, interception of rainfall and surface and subsurface storage capacities are directly influenced by the vegetation cover within a catchment (Battany and Grismer, 2000).

Spatial correlation is used to derive dependencies between various physiographic and climatic factors (Govorov et al., 2017). The relationship between runoff and contributing factors has always been complicated. There is a need for better understanding of these factors influencing runoff over uneven geographical distribution (Kirkby et al.,
2002). Present study investigated the spatial variation of climatic and physiographic factors and their influence on surface runoff. The derived correlation was used to develop statistically sound regression model to describe the relationship between runoff and contributing factors. Moreover, rainwater harvesting is an exigency for Pakistan due to critically intensifying water scarcity (Javed et al., 2016). Present study also identified potential rainwater harvesting sites in Rawalpindi district.

\section{Material and Methods}

\section{The study area}

The focus of present study was district Rawalpindi, situated at northern part of Punjab province, Pakistan. The district is spread over an area of 5,285 square kilometres. It comprises of seven administrative territories (tehsils) namely Rawalpindi, Taxila, Gujar Khan, Kalar-Syedan, Kahuta, Kotli Sattian and Murree (Figure 1). District Rawalpindi is situated at $33.4095{ }^{\circ} \mathrm{N}$ latitude and 72.9933 ${ }^{\circ} \mathrm{E}$ longitude. The elevation ranges between 300 and 2790 meters above the sea level. Climate varies between various

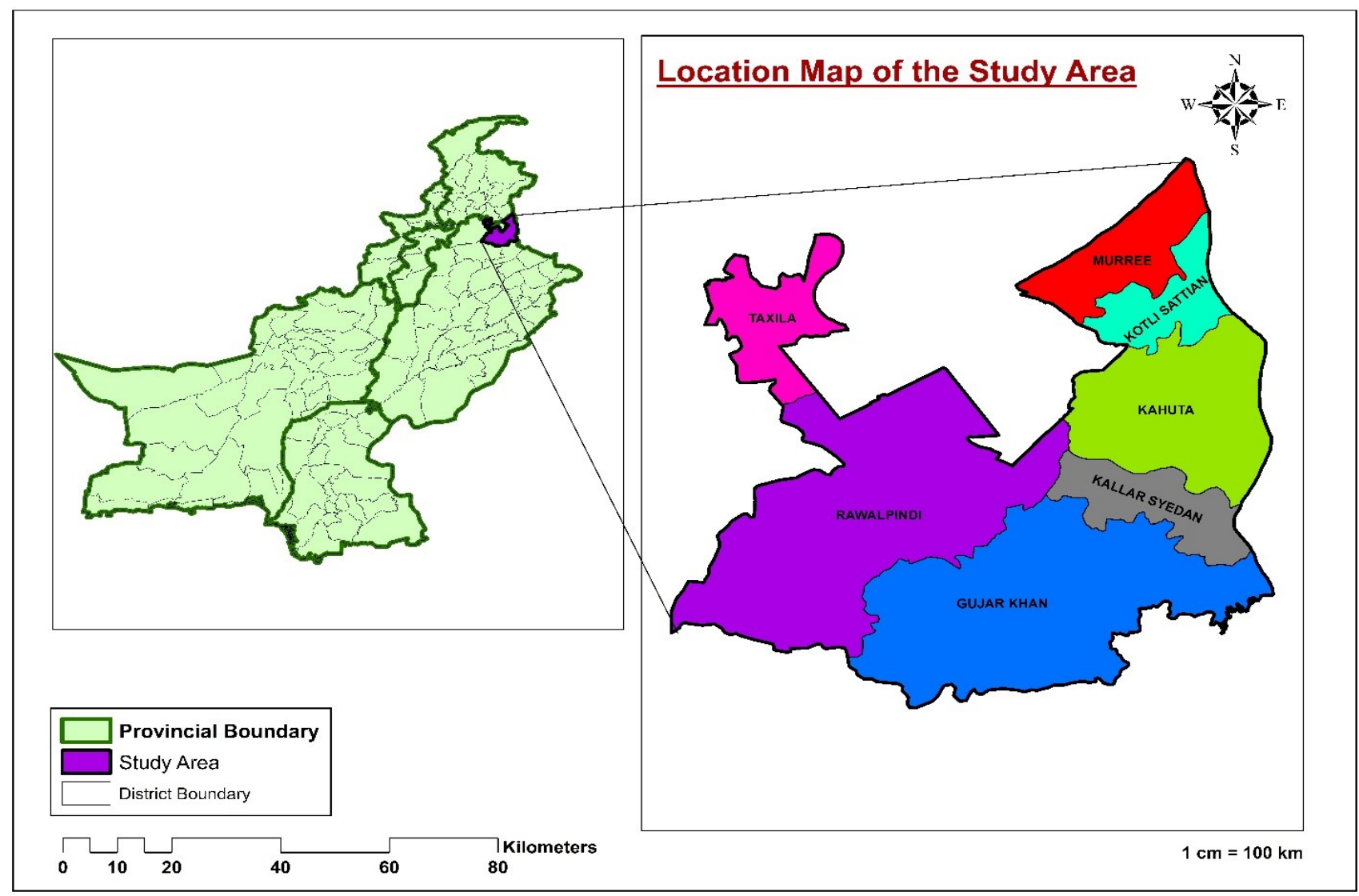

Figure 1: Map of the study area 


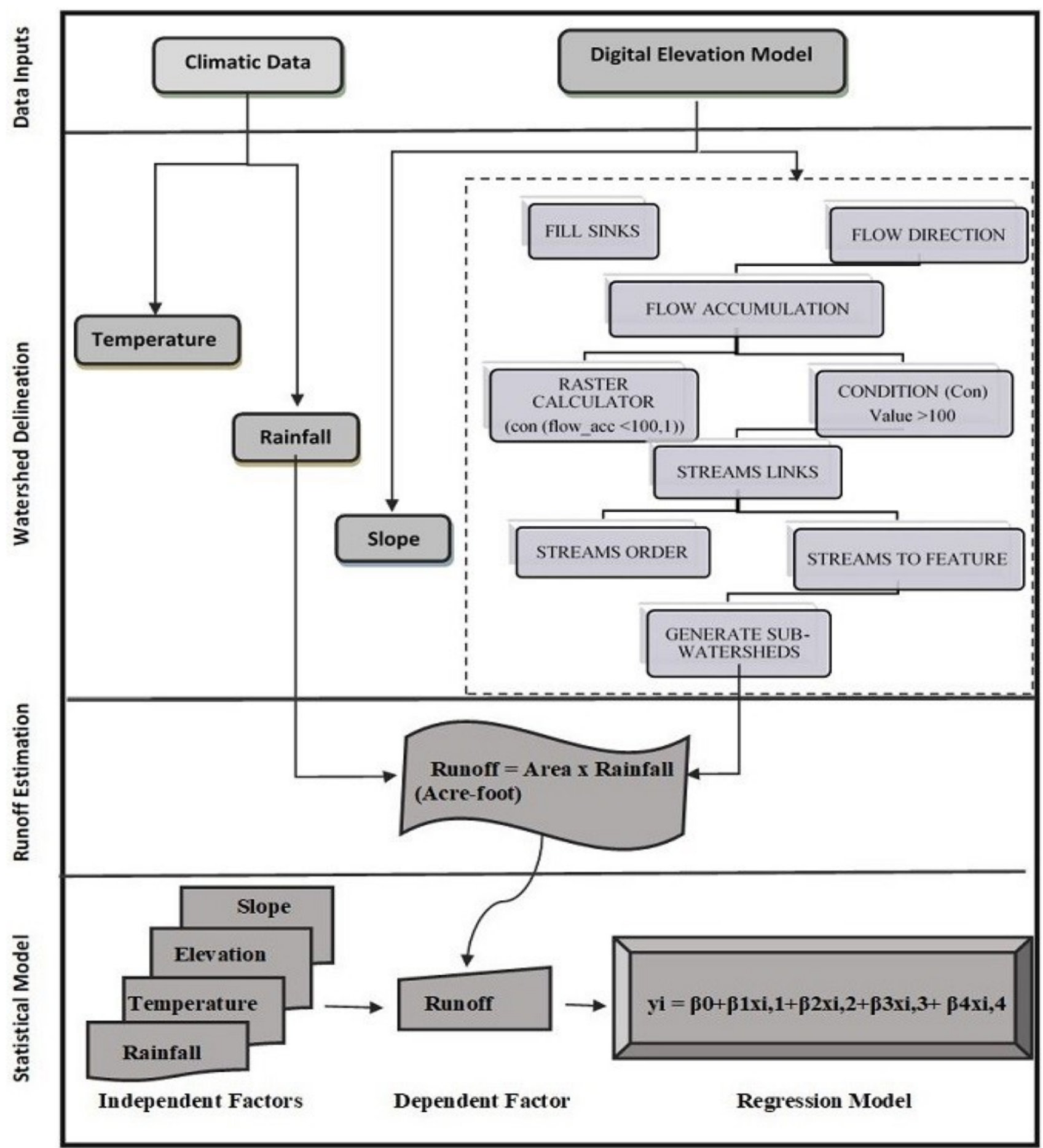

Figure 2: Flow chart of research design

parts of the district. Northern part of the district has severe winter and mild summer (e.g. Murree) while Southern part has hot summer and moderate winter (e.g. Gujar Khan). The mean maximum temperature ranges from $25.6{ }^{\circ} \mathrm{C}$ to $39.4^{\circ} \mathrm{C}$ in June and the mean minimum temperature ranges from 3.2 ${ }^{\circ} \mathrm{C}$ to $16.7^{\circ} \mathrm{C}$ in January. Mean annual precipitation is 1550 
mm with maximum in tehsil Murree. The topography of the land mainly comprises of hills whereas southern part of district is generally plain (DOI, 2012). The northern part is located in the mountainous terrain of Margala hills, Hazara and Kala Chitta Ranges. The terrain gradually falls off towards the Kurang River in the East and Lai Nullah in the West that joins the Soan River in the Southern side (EIA, 2005).

\section{Study design}

The rainfall and temperature records for the period of 30 years (1988-2008) were obtained from Pakistan Meteorological Department (PMD) Islamabad. These records were used for mapping of climatic factors. ASTER DEM of 30 meters spatial resolution was obtained from the United States Geological Survey (USGS website: https://earthexplorer.usgs.gov/). The DEM was utilized in estimation and mapping of physiographic factors. Watershed delineation and runoff estimation were performed using DEM and climatic data. The models were generated for runoff prediction based on influencing factors (rainfall, temperature, slope and elevation). Data flow in present study is given in Figure 2.

\section{Mapping of influencing factors}

Hydrology toolset of ArcGIS 10.2.2 was used for the interpolation of mean annual rainfall and mean annual temperature of the study area. Observatory stations for climatic data (temperature and rainfall) of the study area are shown in Figure 3. Since, the point data was available; Inverse Distance Weight (IDW) interpolation method was used. The maps of climatic factors were generated. The DEM was used as a source of elevation data for the study area. Slope was calculated from DEM using spatial analyst

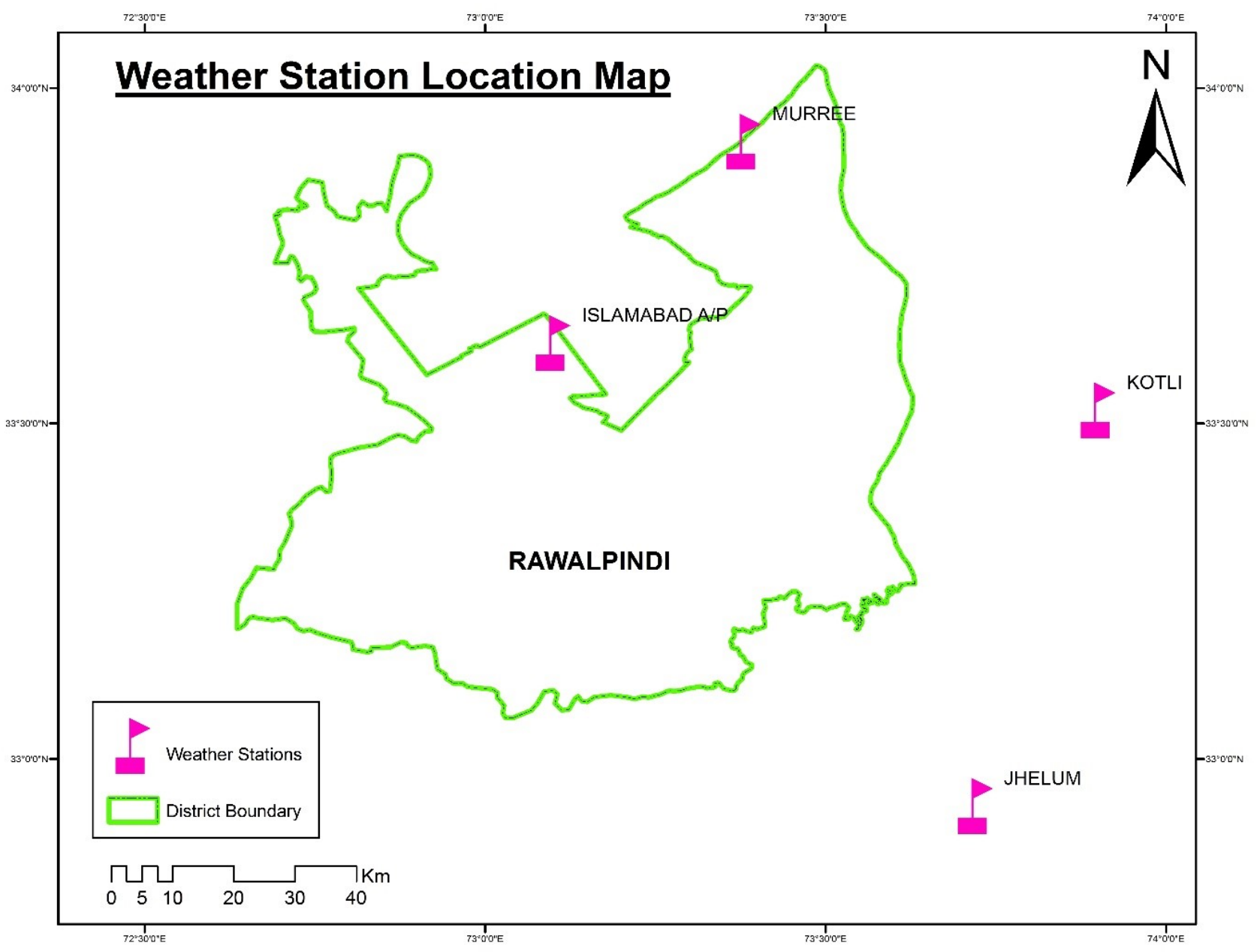

Figure 3: Location of weather stations in the study area 

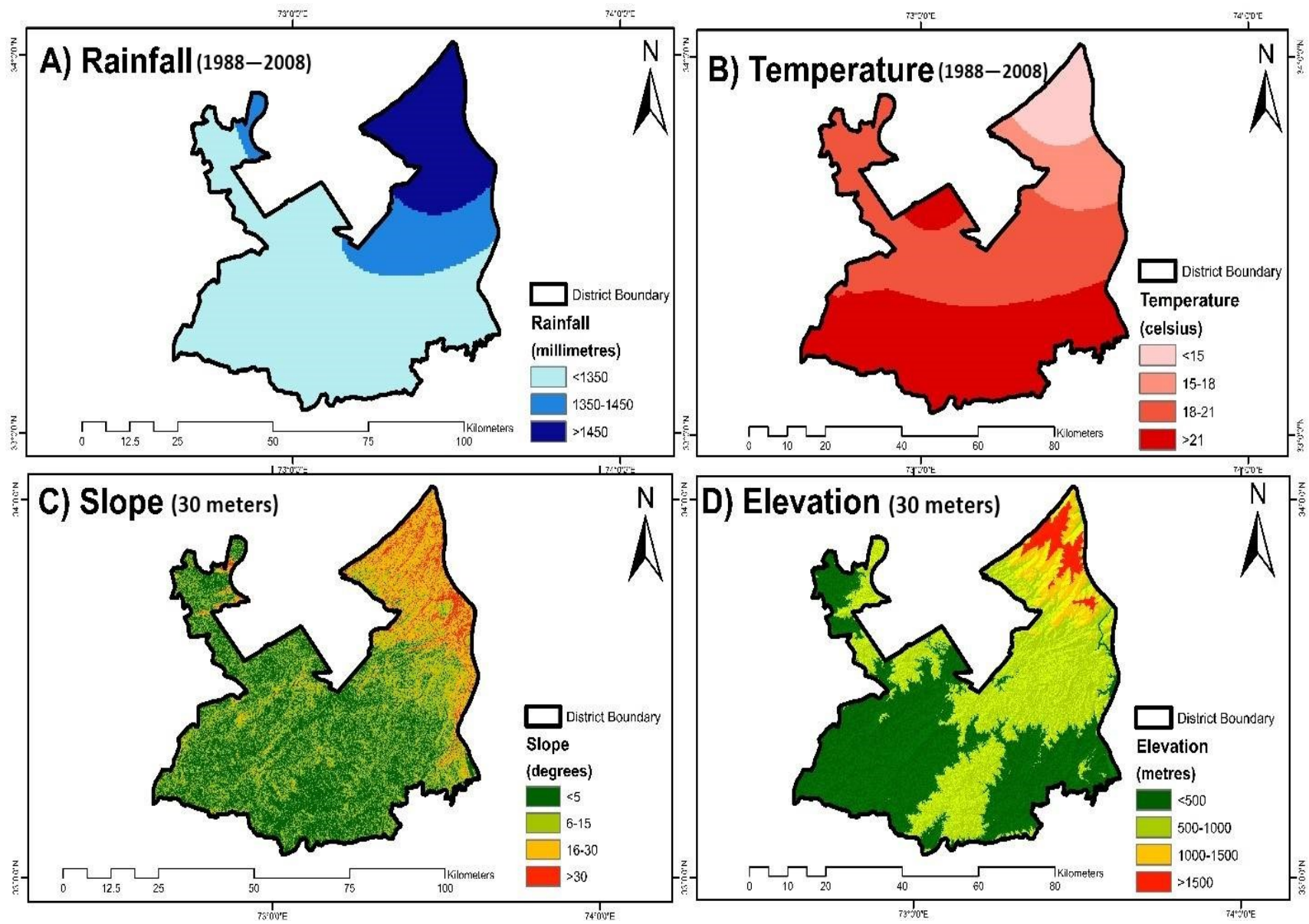

Figure 4: Spatial map of influencing factors for the study area

tool of hydrology toolset in ArcGIS 10.2.2. Maps of influencing factors (rainfall, temperature, slope and elevation) of the study area are shown in Figure 4.

\section{Watershed delineation and runoff estimation}

Hydrology toolset of ArcGIS 10.2.2 was used for assessment and modeling of hydrological characteristics. DEM was used as an input for computing elevation statistics for the watershed delineation. Various drainage patterns along with channel networks, channel properties (flow direction, flow accumulation and stream definition) together with size, length and slope were obtained. Stream network was delineated by using the output from flow accumulation tool of hydrology toolset. The stream order tool was used to assign numeric order to links in a stream network and finally watersheds were delineated from stream order.

A variety of models are available for estimating runoff generated by rainfall e.g. empirical models, conceptual models and physical models (Sitterson et al., 2017). As spatial variability is not considered in conceptual models and large amount of data is required to run the physical models: Therefore, empirical modelling approach was employed in this study because of its simplicity in calculations and implementation (Dawson \& Wilby, 2001; Pechlivanidis et al., 2011). Net runoff from an impervious catchment surface was estimated utilizing the precipitation records and size of catchment adjusted by its runoff coefficient (Lancaster and Marshall, 2008). Runoff calculation method is indicated in Equation 1.

$Q=K \times P \times A$

Equation 1

where,

$\mathrm{Q}=$ Runoff (liters)

$\mathrm{P}=$ Precipitation $(\mathrm{mm})$

$$
\mathrm{A}=\text { Area of catchment }\left(\mathrm{m}^{2}\right)
$$$$
\mathrm{K}=\text { Constant }
$$

The value of constant is less than or equal to 1 . It is generally calculated by weighted average percentage of the 
land cover. The runoff for each catchment was calculated in the raster calculator of ArcGIS 10.2.2 using Equation 1. The runoff potential was converted from liters to Acre-foot using 'SI' unit as:

1 Acre-foot $=1233481.85$ liters.

\section{Statistical analysis}

Spatial correlation between runoff and the contributing factors was calculated in ArcGIS 10.2.2 using band collection statistics tool and correlation matrixes were generated. Correlation matrix indicated the strength between the variables at various ranges. Maps of the study area were divided in total 116 grids of resolution ( $6750 \times 6750$ meters $)$ to extract the sampling data for statistical analysis. Logarithmic transformation was used for ease of interpretation and it helped to reduce the skewness (Manikandan, 2010). Multiple linear regression analysis was performed on data and model was developed. The regression model used influencing factors i.e. rainfall, temperature, slope and elevation to predict the outcome of runoff. Co-efficient of determination $\left(\mathrm{R}^{2}\right)$ was calculated to check closeness of data to the fitted regression line.

Table 1: Results of watershed delineation in the study area

\begin{tabular}{ll}
\hline Area of district (sq. km) & 5285 \\
\hline Number of watersheds & 2687 \\
\hline Streams length $(\mathrm{km})$ & 7818 \\
\hline Net runoff $(\mathrm{MAF})$ & 2.47 \\
\hline
\end{tabular}

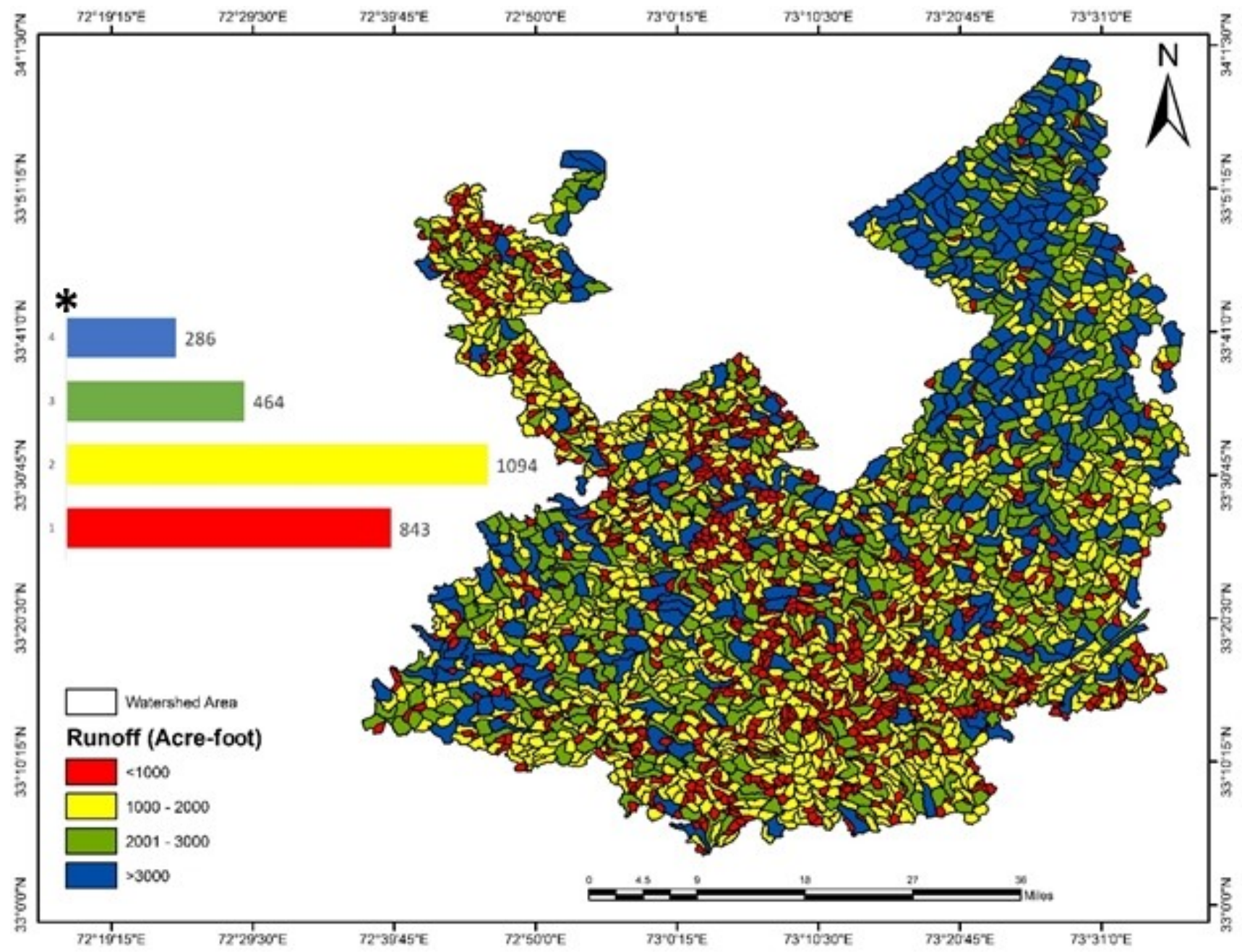

Figure 5: Runoff potential/yield of sub-watersheds in the study area 


\section{Results and Discussion}

\section{Watershed delineation and estimated runoff}

Hydrologic model with the coordination of GIS provided the delineated watersheds. In total 2687 subwatersheds were delineated with stream length of $7818 \mathrm{~km}$ in the study area as given in Table 1. The net runoff estimated in all the watersheds was found to be 2472000 acre-ft per annum. The bifurcation of the runoff indicated that 843 watersheds in the area had runoff less than 1000 acre-ft. per annum while 286 watersheds had maximum runoff of beyond 3000 acre-ft. Maximum number of watersheds (1094) had runoff greater than and equal to 1000 acre- $\mathrm{ft}$ to the range of less than and equal to 2000 acre- $\mathrm{ft}$. The number of watersheds having runoff between 2000 to 3000 acre-ft per annum was found to be 464 (Figure 5). Past studies stressed upon the need of rainwater harvesting in the Pothwar region to meet the increasing demands of water. There is large number of small basins in Pothwar region suitable for water harvesting taking into consideration the amount of runoff generated (Ghani et al., 2013). Javaid et al. (2016) stressed to explore and identify the best rain water in ArcGIS 10.2.2 as shown in Figure 6. The highest correlation (0.7) was found between runoff and area of watershed. This illustrated that water flow in a watershed was largely dependent on the catchment area (Rajib and Venkatesh, 2015). The time for draining the runoff to the outlet is longer in larger watershed compared to small watershed (Balasubramanian, 2017). Climatic factors including rainfall and temperature showed remarkable correlation with runoff as well. Rainfall and runoff indicated positive correlation of 0.35 . Shang et al. (2019) also verified that there was a direct correlation between rainfall and runoff as the runoff changes were consistent with the rainfall changes. However, the correlation between runoff and temperature was negative (-0.36). McCab and Wolock (2011) also found that increase in temperature resulted in reduction of surface runoff.

Physiographic factors including slope and elevation indicated positive correlation of 0.27 and 0.25 , respectively, with surface runoff but their effect was slightly low compared to the climatic factors. The amount of runoff increases in the sloppy watersheds due to greater velocity of runoff (Balasubramanian, 2017). Vegetation cover on the slope of

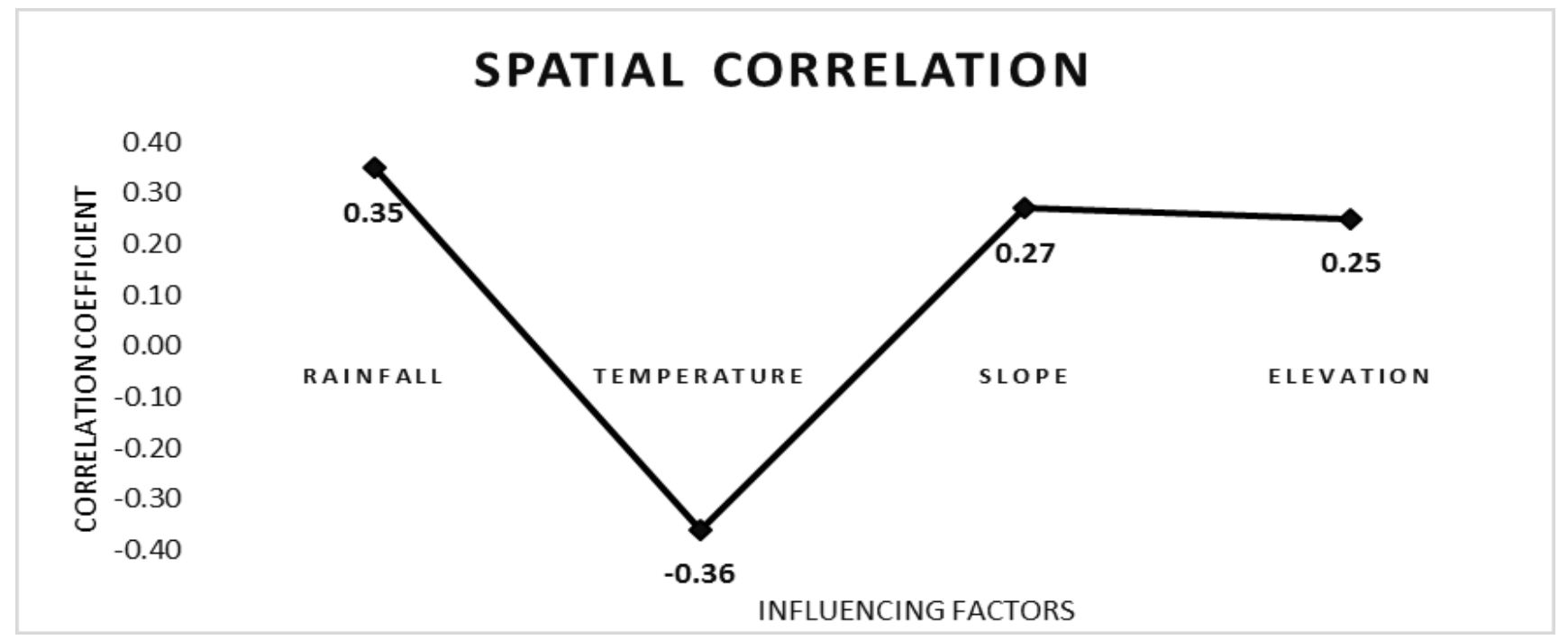

Figure 6: Spatial correlation between runoff and influencing factors in the study area

harvesting sites to fulfill the increasing demands of food and agriculture activities in the region. Present study properly highlighted the potential and suitability of rainwater harvesting sites in the district of Rawalpindi.

\section{Spatial correlation between run-off and contributing factors}

The spatial correlation between surface runoff and contributing factors (climatic and physiographic) was derived watershed can also play a significant role on the amount of runoff generated (Rashid et al., 2015). Garcia-Martino et al. (1996) also stated that rate of surface runoff was positively and significantly correlated with elevation of watershed.

The values of correlation were not significantly high for climatic and physiographic factors except area of watershed because spatial variability of these factors was quite complicated. Therefore, separate correlation matrix was 
generated for each factor for better understanding of strength between runoff and each influencing factor.

\section{Spatial correlation between run-off and climatic factors}

The spatial correlation matrix indicated that correlation (0.17) existed between rainfall and runoff at the watersheds receiving rainfall between 1250 to $1350 \mathrm{~mm}$. However, strength between rainfall and runoff increased as the amount of rainfall increased as shown in Figure 7(A). The dependency between rainfall and runoff was found to be high $(0.31)$ at the watersheds receiving maximum rainfall $(>1450 \mathrm{~mm})$. High rainfall yields high runoff and there is a direct correlation between rainfall and runoff as stated by Mohamadi and Kavian (2015).

Strength of relationship between runoff and temperature was high at watersheds with mean temperature less than $15^{\circ} \mathrm{C}$. However, the value of correlation coefficient turned to negative with increase in temperature and vice versa. The values were 0.29 and 0.20 when temperature was below $18^{\circ} \mathrm{C}$ whereas -0.13 and -0.23 when temperature was above $18^{\circ} \mathrm{C}$ as shown in Figure 7(B). High temperature tends to increase the rate of evapotranspiration which generally results in reduction of surface runoff (McCab and Wolock, 2011). Shang et al. (2019) found that increase in evapotranspiration is not coinciding with the variability of climatic factors (temperature, rainfall). When the amount of rainfall decreases coupled with increase in temperature, the amount of runoff reduces significantly. However, the amount of runoff increases with the increase in precipitation along with decrease in temperature.

\section{Spatial correlation between run-off and physiographic factors}

Correlation matrix depicted that dependency between runoff and slope was negative $(-0.25)$ in the areas where slope was less steep $(<5$ degree $)$. As the slope became steeper i.e., $>15$ degree, the strength between runoff and slope was found to be positive $(0.20)$ in those watershed areas shown in Figure 7(C). According to Fang et al. (2008), the increase in slope steepness and length resulted in

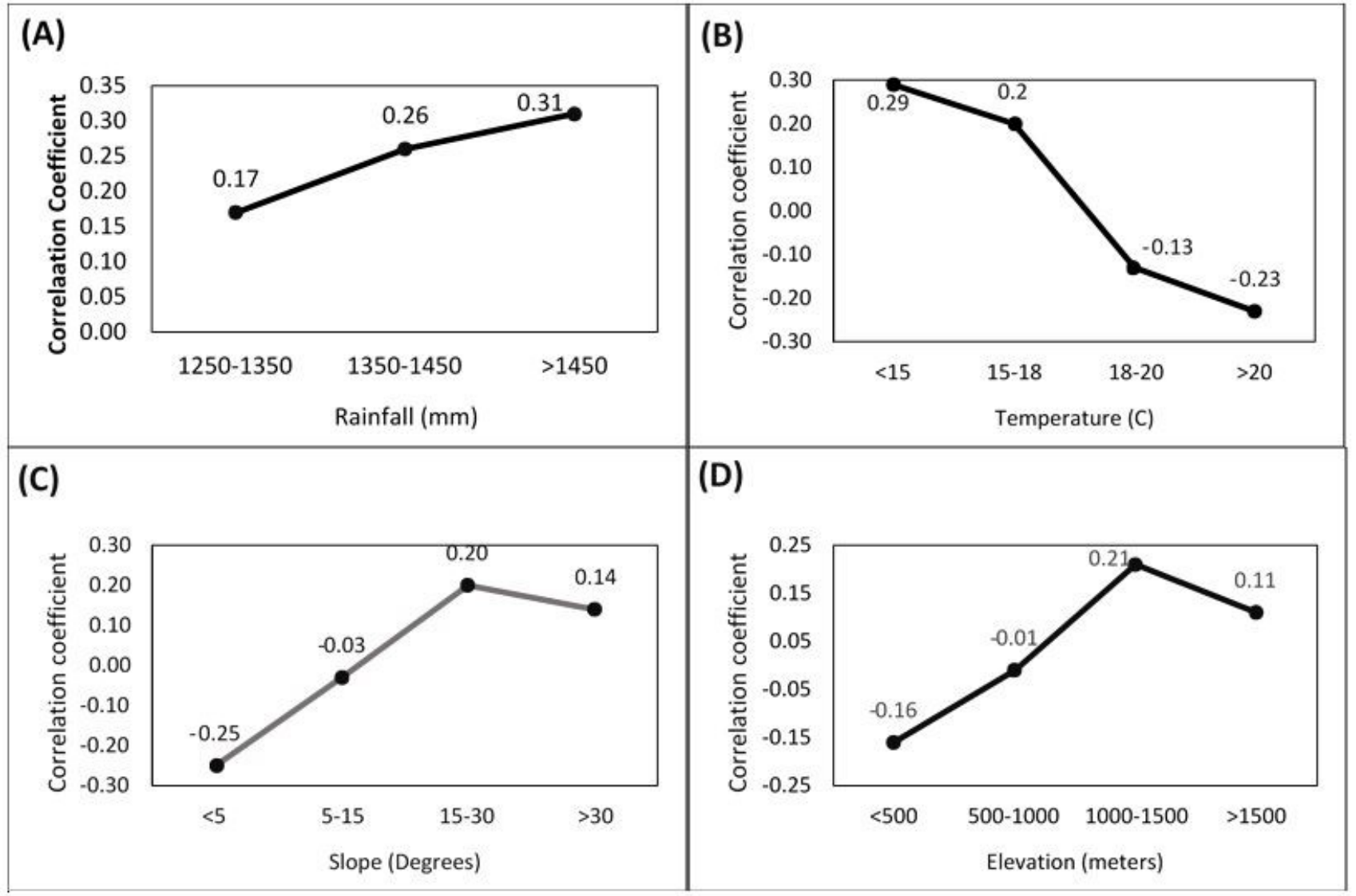

Figure 7: Spatial correlation among runoff and contributing factors 
increased surface runoff due to encrusted surface and higher soil moisture content on downslope side. However, the correlation between runoff and slope, dropped from 0.20 to 0.14 in the areas where slope steepness exceeded 30 degree. Warrington et al. (1989) stated that there was a range of critical slope (30 degree) beyond which the rate of infiltration increased (due to low flow density) and the amount of runoff slightly decreased.

Runoff and elevation showed similar trend as runoff and

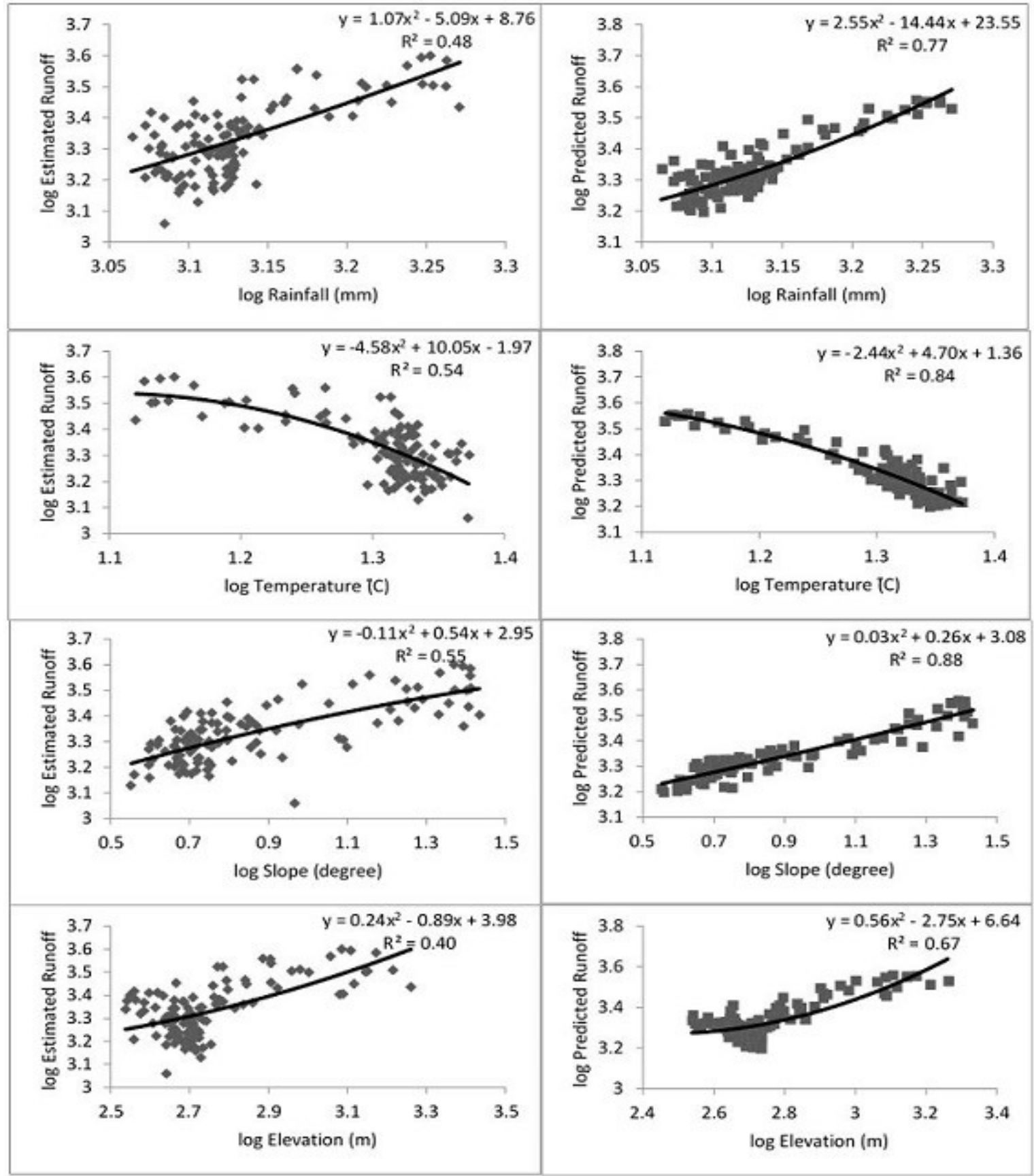

Figure 8: Line fit plots of runoff yield and influencing factors 
slope. Spatial correlation was negative $(-0.16)$ between runoff and elevation at the areas where elevation was low $(<500$ meters) as shown in Figure 7(D). Positive correlation (0.21) was found between runoff and watershed areas located at higher elevation (1000 to 1500 meters). The runoff increases with rise in elevation because rainfall is associated with the elevation and increased rainfall leads to higher runoff (Garcia-Martino et al., 1996). The dependency between runoff and elevation slightly dropped (0.11) as the elevation further increased from 1500 meters in the study area.

\section{Regression models of surface runoff and influencing factors}

The four-factor multiple regression analysis was performed using the climatic and physiographic factors (rainfall, temperature, slope and elevation) as independent variables and runoff as dependent. From regression model, $\mathrm{R}^{2}$ was found to be 0.62 or 62 percent variance in runoff was explained by the geographical and climatic factors. It was evident from the analysis that maximum change in runoff $(-1.36$ acre-ft) would occur with one unit change in temperature. The change in one unit $(1 \mathrm{~mm})$ of rainfall would result in minimum change in runoff $(0.15$ acre-ft). The regression model showing the relationship between surface runoff and influencing factors is given as follows:

Runoff $=5.5+0.15 \log ($ rainfall $)-1.36 \log ($ temperature $)$

$+0.24 \log ($ slope $)-0.39 \log ($ elevation $) \quad$ Equation 2

The relationship between runoff and influencing factors was derived using linear, polynomial, power and exponential regression models. The analysis indicated that one-degree polynomial curve best fitted the data. Maximum change ( 88 percent) found in runoff can be explained by slope. Whereas, rainfall, temperature and elevation explained 77 percent, 84 percent and 67 percent variance found in runoff respectively. The regression models for all the influencing factors for both estimated and predicted runoff is given in Figure 8 .

\section{Conclusions}

Present study provided better understanding of interrelationship between surface runoff and influencing factors. District Rawalpindi has a great potential of rainwater harvesting as surface runoff generated by rainfall was estimated to be 2472000 acre-ft per annum. However, the strength or dependency of surface runoff with physiographic and climatic factors varies spatially within the region. Slope explained maximum change in runoff followed by temperature, rainfall and then elevation. Furthermore, this study presented a statistical model to predict outcome of surface runoff in watersheds using the influencing factors. The results highlighted how climatic and physiographic factors generating runoff within watersheds fit together. Maximum change in runoff was predicted by one unit change in temperature followed by elevation, slope and then rainfall. The outcomes of the study can be utilized to formulate GIS based models describing the location and potential of rainwater harvesting sites within the watersheds as affected by climate and physiography of the area.

\section{References}

Balasubramanian, A. 2017. Surface Water Runoff. Centre for Advanced Studies in Earth Science, University of Mysore, India. $10 \mathrm{p}$.

Battany, M.C. and M.E. Grismer. 2000. Rainfall runoff and erosion in Napa Valley vineyards: Effects of slope, cover and surface roughness. Hydrological Processes 14: 1289-1304.

Dawson, C.W. and R.L. Wilby. 2001. Hydrological modelling using artificial neural networks. Progress in physical Geography 25: 80-108.

Deng, Y., J.P. Wilson and B.O. Bauer. 2007. DEM resolution dependencies of terrain attributes across a landscape. International Journal of Geographical Information Science 21: 187-213.

DOI. 2012. District Pre-investment Study. Directorate of Industries, Punjab. p.87. [Accessed on 06 June 2018], www.doi.punjab.gov.pk/system/files/Rawalpindi.pdf

dos Santos, J.C.N., E.M. de Andrade, P.H.A. Medeiros, M.J.S. Guerreiro and H.A. de Queiroz Palácio. 2017. Effect of rainfall characteristics on runoff and water erosion for different land uses in a tropical semiarid region. Water Resources Management 31: 173-185.

Du, J. and C.X. Shi. 2012. Effects of climatic factors and human activities on runoff of the Weihe River in recent decades. Quaternary International 282: 58-65.

EIA. 2005. Rawalpindi Environmental Improvement Project in the Islamic Republic of Pakistan. Summary Environmental Impact Assessment. Government of Pakistan. 54 p.

Fang, H.Y., Q.G. Cai, H. Chen and Q.Y. Li. 2008. Effect of rainfall regime and slope on runoff in a gullied loess region on the Loess Plateau in China. Environmental Management 42: 402-411.

Garbrecht, J. and L.W. Martz. 1997. The assignment of drainage direction over flat surfaces in raster digital elevation models. Journal of hydrology 193: 204-213.

Garcia-Martino, A.R., G.S. Warner, F.N. Scatena and D.L. Civco. 1996. Rainfall, runoff and elevation relationships in the Luquillo Mountains of Puerto Rico. Caribbean Journal of Science 32: 413-424. 
Garg, V., B.R. Nikam, P.K. Thakur and S.P. Aggarwal. 2013. Assessment of the effect of slope on runoff potential of a watershed using NRCS-CN method. International Journal of Hydrology Science and Technology 3: 141-159.

Ghani, M.W., M. Arshad, A. Shabbir, N. Mehmood and I. Ahmad. 2013. Investigation of potential water harvesting sites at Potohar using modeling approach. Pakistan Journal of Agricultural Sciences 50: 723-729.

Govorov, M., V. Putrenko and G. Gienko. 2017. Mining spatial patterns of distribution of Uranium in surface and ground waters in Ukraine. p.520-546. In: Handbook of Research on Geographic Information Systems Applications and Advancements. IGI Global

Javaid, A., K. Ghauri, B. Muneer and M. Nasar-u-Minallah. 2016. Criteria maps for rainwater harvesting in potohar region. Science International 28: 2617-2620.

Jenson, S.K. and J.O. Domingue. 1988. Extracting topographic structure from digital elevation data for geographic information system analysis. Photogrammetric Engineering and Remote Sensing 54: 1593-1600.

Kirkby, M., L. Bracken and S. Reaney. 2002. The influence of land use, soils and topography on the delivery of hillslope runoff to channels in SE Spain. Earth Surface Processes and Landforms: The Journal of the British Geomorphological Research Group 27(13): 1459-1473.

Lancaster, B. and J. Marshall. 2008. Rainwater harvesting for drylands and beyond (Vol. 1). Tucson: Rainsource Press. 12 p. Arizona, USA.

Manikandan, S. 2010. Data transformation. Journal of Pharmacology and Pharmacotherapeutics 1: 126-127.

McCabe, G.J. and D.M. Wolock. 2011. Independent effects of temperature and precipitation on modeled runoff in the conterminous United States. Water Resources Research 47(11).

Mekonnen, M., A.M. Melesse and S.D. Keesstra. 2016. Spatial runoff estimation and mapping of potential water harvesting sites: A GIS and remote sensing perspective. p.565-584. In: Landscape Dynamics, Soils and Hydrological Processes in Varied Climates. Springer International Publishing. Northwest Ethiopia.

Meshram, S.G., S.K. Sharma and S. Tignath. 2017. Application of remote sensing and geographical information system for generation of runoff curve number. Applied Water Science 7(4):1773-1779.

Mohamadi, M.A. and A. Kavian. 2015. Effects of rainfall patterns on runoff and soil erosion in field plots. International Soil and Water Conservation Research 3: 273-281.
Munyao, J.N., C.M.M. Mannaerts and M. Krol. 2010. Use of satellite products to assess water harvesting potential in remote areas of Africa. Land Degradation and Development 22: 359-372.

Pechlivanidis, I.G., B.M. Jackson, N.R. McIntyre and H.S. Wheater. 2011. Catchment scale hydrological modelling: A review of model types, calibration approaches and uncertainty analysis methods in the context of recent developments in technology and applications. Global NEST journal 13: 193-214.

Rajib, A. and M. Venkatesh. 2015. Effect of watershed characteristics on runoff generation and streamflow response. R Water Module 4, Lyles School of Civil Engineering, Purdue University. pp. 1-7.

Rashid, M., R. Kausar, S. Alvi and M.R. Sajjad. 2015. Assessment of runoff and sediment losses under different slope gradients and crop covers in semi-arid watersheds. Soil \& Environment 34(1): 75-81.

Shang, X., X. Jiang, R. Jia and C. Wei. 2019. Land use and climate change effects on surface runoff variations in the upper Heihe river basin. Water 11(2):344.

Shi, Z.H., L.D. Chen, N.F. Fang, D.F. Qin and C.F. Cai. 2009. Research on the SCS-CN initial abstraction ratio using rainfall-runoff event analysis in the Three Gorge area, China, Catena. 77:1-7.

Sitterson, J., C. Knightes, R. Parmar, K. Wolfe, M. Muche and B. Avant. 2017. An overview of rainfall-runoff model types an overview of rainfall-runoff model types. US Environmental Protection Agency pp. 0-29. Washington DC, USA.

USGS United States Geological Survey. The USGS Water Science School. Available at: https://water.usgs.gov/edu/watershed.html [Accessed: 2017 October 4]

Warrington, D., I. Shainberg, M. Agassi and J. Morin. 1989. Slope and phosphogypsum's effects on runoff and erosion. Soil Science Society of America Journal 53: 1201-1205.

Wu, S., J. Li and G.H. Huang. 2007. Modeling the effects of elevation data resolution on the performance of topography-based watershed runoff simulation. Environmental Modelling \& Software 22: 1250-1260.

Younger, P.L., S.A. Banwart and R.S. Hedin. 2002. Mine water hydrology. p.127-270. In: Mine Water. Springer, Dordrecht. Netherlands. 